\title{
Os Desafios do Ensino da Disciplina Contabilidade de Custos em Face do Panorama Contemporâneo da Economia Brasileira
}

\author{
The Discipline of Education Challenges Cost Accounting in view of the Panorama of \\ Contemporary Brazilian Economy
}

\author{
José Luiz Nunes Fernandes \\ joseluiz@uscs.edu.br \\ USCS/UFPA
}

Barbara Adria Farias Fernandes
Bbarbaraadria@yahoo.com.br USCS

\author{
Darticléia Rocha Soares \\ dartisoares@terra.com.br \\ USCS
}

Jairo Rocha Soares

darti@uscs.edu.br USCS

\author{
Laercio Baptista da Silva \\ lasilva@uscs.edu.br \\ USCS
}

\begin{abstract}
RESUMO
O objetivo deste trabalho é verificar como está ocorrendo à adaptação do conteúdo e o método de ensino e de que maneira a disciplina Contabilidade de Custos está sendo ministrada no curso de graduação em Ciências Contábeis em face do panorama econômico da perda do peso relativo da indústria manufatureira no conjunto da economia brasileira. Para se atingir o objetivo proposto, utilizou-se a metodologia que se classifica como exploratória, ou seja, os docentes foram submetidos a um questionário com questões fechadas para se apurar se o método de ensino e o conteúdo abordado estão preparando os alunos para o mercado de trabalho. O resultado da pesquisa e sua contribuição permitem incursionar que, por parte dos docentes, a disciplina Contabilidade de Custos deve ser explorada de forma diferenciada e os conteúdos adaptados à realidade do mercado de trabalho, com exercícios e indicações bibliográficas, no que concerne à contabilização e análise dos fatos relacionados aos custos das empresas prestadoras de serviços e das empresas atuantes no setor agropecuário. Quanto aos alunos que cursam a disciplina Contabilidade de Custos, há evidências de que não estão sendo preparados satisfatoriamente para trabalhar em empresas que oferecem maior oportunidade de trabalho no panorama econômico contemporâneo. Apesar de ter limitações, espera-se com esta pesquisa contribuir para que o ensino da disciplina Contabilidade de Custos esteja em sintonia com o panorama contemporâneo brasileiro de desindustrialização econômica.
\end{abstract}

Palavras-Chaves: Ensino da Contabilidade de Custos. Empresas prestadoras de serviços. Ensino adequado ao mercado de trabalho.

\section{ABSTRACT}

The objective of this work is to see how is going to adapt the content and method of 
teaching and how Cost Accounting course is being taught in the undergraduate degree in Accounting in the face of the economic outlook in relative weight of manufacturing industry in the Brazilian economy. To achieve the proposed objective, we used a methodology that is classified as exploratory, ie, teachers underwent a questionnaire with closed questions to determine if the method of teaching and the content covered are preparing students for the market job. The result of the research and its contribution to allow incursion on the part of teachers, Cost Accounting discipline should be exploited in different ways and adapted to the reality of the labor market content with exercises and bibliographical information, regarding the accounting and analysis related to the costs of service providers and companies in the agricultural sector facts. As for students who attend Cost Accounting discipline, there is evidence that they are not being adequately prepared to work in firms that offer greater opportunity to work in the contemporary economic landscape. Despite limitations, we expect this research to contribute to the teaching of the subject Cost Accounting is in tune with the contemporary panorama of Brazilian economic deindustrialization .

Key Words: Teaching Cost Accounting. Service providers. Appropriate education to the labor market.

Artigo recebido em: 03/06/2013; Aceito em: 05/01/2014

\section{INTRODUÇÃO}

Por muito tempo, a disciplina Contabilidade de Custos, quando ministrada no plano de graduação, nas áreas das Ciências Sociais aplicadas, era direcionada, principalmente, para preparar os cidadãos para os desafios a serem enfrentados no mercado de trabalho, ou seja, informações voltadas para a empresa industrial e que retratava os processos de industrialização de bens corpóreos.

A ideia era a de que o conhecimento fosse aplicado na área de custos das empresas industriais, no segmento de manufatura, de transformação, preparando relatórios úteis e tempestivos para o processo decisório. Para tanto, seria necessário o domínio de assuntos, tais como: custos, custeios, margem de contribuição, rateio, rastreamento e outros instrumentos de custos voltados ao processo de manufatura que eram e continuam sendo fundamentais (MARION; RIBEIRO, 2011). Embora o panorama do setor de transformação tenha mudado, esses conhecimentos não perderam a relevância, mas adquiriram-se novas formas de aplicá-los.

Em sala de aula, tornou-se desafiador induzir os alunos a vislumbrarem cenário, por exemplo, de chão de fábrica, onde os fatores de produção e os custos incorrem, com o objetivo de tornar o aprendizado mais próximo da realidade das empresas industriais. Porém, esse cenário tem sido cada vez mais escasso, inabitado e de difícil visibilidade.

Para Medeiros, Lima e Araújo (2005) a concepção da aprendizagem reflete a repetição de algo visto anteriormente, de modo que a existência de dificuldade pode estar fundamentada na falta de vivência e de pré-requisito, entre outros pressupostos. $\mathrm{O}$ educador precisa aliar sua formação teórica à pedagógica, a fim de conduzir o futuro contador a uma vida profissional competente e favorável à sociedade, em todos os aspectos. (PADOAN; CLEMENTE, 2010). 
Itoz e Mineiro (2005) explicam que, a pedagogia moderna tem como pilar a sua relação com a realidade contemporânea e com os conteúdos significativos, de tal forma que o aluno, ao perceber a artificialidade e a não aplicabilidade do currículo a ser estudado, e não sentindo necessidade de aprender aquele conteúdo, estuda-o de forma vazia, somente para a obtenção de notas. Compreende-se, assim, que só é passível de ser aprendido um conteúdo relevante.

Desse modo, observa-se a desindustrialização ou a perda do peso relativo da indústria manufatureira no conjunto da economia como um fenômeno não cíclico, mas estrutural e de longo prazo, fato que é merecedor de reflexão. No outro lado da moeda, nota-se que o avanço tecnológico tem propiciado expressivos ganhos de produtividade, haja vista o agronegócio que tem obtido excelentes resultados mediante pesquisas e ações inovadoras. Além disso, o Brasil tem se destacado no cenário econômico global pela exploração de minérios, óleo e gás. O setor de serviços tem apresentado resultados pujantes, em especial as telecomunicações, hotelaria, turismo e informática, aspectos que também merecem reflexão, quando a proposta é ministrar a disciplina Contabilidade de Custos, sobretudo, no plano da graduação.

Malan (2013) relata que, na maioria dos países em desenvolvimento, os quais procuraram avançar na senda da industrialização, houve significativas intervenções do poder público em apoio à atividade industrial. Apesar disso, pouquíssimos chegaram a desenvolver massa crítica suficiente na indústria ou no capital humano requerido para o desenvolvimento industrial sustentado e competitivo internacionalmente.

É essa massa crítica do capital humano citada por Malan (2013) que a presente pesquisa intenciona fomentar e instigar a reflexão. Assim, a questão de pesquisa é: Os conteúdos e as propostas de ensino da disciplina Contabilidade de Custos, no plano da graduação, no curso de Ciências Contábeis, estão em sintonia com o que requisita o mercado de trabalho para o profissional de Contabilidade que atua na produção de informações sobre custos?

O objetivo geral é: Averiguar de que maneira a disciplina Contabilidade de Custos está sendo ministrada no curso de graduação em Ciências Contábeis, em face do panorama econômico de desindustrialização brasileira.

Especificamente, os pesquisadores tentarão averiguar se os docentes responsáveis por ministrarem a disciplina Contabilidade de Custos estão buscando a sinergia, baseandose no novo panorama econômico nacional, caracterizado pela perda do peso relativo da indústria manufatureira no conjunto da economia e, tendo por desafio o de preparar o aluno a esse contemporâneo mercado de trabalho.

Espera-se que essa pesquisa possa contribuir para o ensino da disciplina Contabilidade de Custos e que esse possa estar em sintonia com o panorama mercadológico contemporâneo brasileiro de desindustrialização econômica.

\section{REFERENCIAL TEÓRICO}

\subsection{O Ensino da Contabilidade de Custos}

A Contabilidade de Custos, no Brasil, como regra, é ministrada no sentido de que os conhecimentos perpassados sejam aplicados na produção de relatórios e soluções de problemas tendo como alvo tradicional a indústria de transformação, ou seja, a indústria que produz bens tangíveis.

É bem provável que tal realidade esteja voltada à origem da Contabilidade de Custos, cujo histórico inicial foi a Revolução Industrial. Marion e Ribeiro (2011), por sua vez,

R. Cont. Ufba, Salvador-Ba, v. 9, n. 1, p. 05 - 21, jan-mar 2015 
descrevem que, no século XVIII, na conhecida época da Revolução Industrial, os proprietários das indústrias manufatureiras europeias começaram a encontrar dificuldades para apurar os resultados e conhecer os custos de fabricação.

Coelho e Lins (2010) relatam que o impacto da revolução industrial ocasionou nos processos contábeis a necessidade de controles mais complexos nas atividades de produção. Os autores supracitados finalizam, afirmando que é impossível se referir à Contabilidade de Custos sem falar em produção.

Foi nesse panorama que surgiu a Contabilidade de Custos como importante instrumento de controle que facilitou a avaliação dos estoques de produtos fabricados. Vale lembrar que a Contabilidade de Custos é parte componente de um ramo maior da Contabilidade, a Contabilidade Gerencial (MARION; RIBEIRO, 2011).

Cardoso, Mário e Aquino (2007) entendem que, não se pode dizer que seja diversa a atuação da Contabilidade de Custos, inserida no que se denomina de maneira mais ampla como Contabilidade Gerencial. Esta última nos remete à principal ênfase dada nesse ramo da Contabilidade: a gerência das organizações.

A Contabilidade Gerencial é o ramo da Contabilidade que gera informações para os usuários internos da organização, quer a empresa seja industrial ou não, porém a raiz é profunda quanto à informação gerencial para as empresas industriais. Nesse sentido, Marion e Ribeiro (2011) afirmam que a contabilidade gerencial surgiu no ambiente industrial, propagando-se por todos os segmentos organizacionais como excelente instrumento de gestão.

O processo ensino e aprendizagem na área de Contabilidade, mais especificamente, na área de custos, deve acontecer naturalmente, pois buscando-se adaptar situações do cotidiano vivenciadas pelo aprendiz com os estudos, faz com que ele adquira habilidades, a fim de habituar-se a mudanças (ITOZ; MINEIRO, 2005).

2.2 Desafios do Ensino da Disciplina Contabilidade de Custos.

Bennis e O'Toole (2012), ao se referirem de forma crítica ao estado de arte dos ensinos de gestão e de contabilidade de custos, expõem que, parte da pesquisa produzida é ótima, mas há poucos elementos baseados em práticas de negócios reais, razão pela qual o foco da educação administrativa está cada vez mais circunscrito e menos relevante para quem atua na prática.

Medeiros, Lima e Araújo (2005) asseguram que uma abordagem cognitiva da aprendizagem se fundamenta em experiências anteriores como facilitadoras da apreensão e retenção dos conteúdos. Em geral, os alunos que são experientes no ambiente empresarial, conseguem assimilar mais rapidamente os conceitos, ainda que não seja incomum se observar forte resistência à sua aceitação, uma vez que, nem sempre, são compatíveis com as suas práticas habituais.

Drucker (1970) ao explicar como a administração ocidental pode aprender com a administração japonesa enfatiza que, o Contador japonês está em constante processo de aprendizado e ligando os processos empresariais a realidade econômica fora da fronteira física da empresa e que, os engenheiros industriais atuam como professores procurando ensinar como se aumenta a produtividade e se aperfeiçoa os processos.

Bursal (1992) ao pesquisar, na Alemanha, o ensino da disciplina Contabilidade de Custos, levando em conta as mudanças no ambiente fabril, descreve que o ensino da disciplina Contabilidade de Custos busca familiarizar o aluno com outras atividades que não sejam exclusivamente fabris, com o objetivo de melhor prepará-lo para mudanças ambientais.

Itoz e Mineiro (2005) expressam que o ensino da Contabilidade de Custos, atualmente, deve ser entendido como um condutor de conhecimentos, sempre na vanguarda de seu tempo e pronto para responder às necessidades de seus usuários.

R. Cont. Ufba, Salvador-Ba, v. 9, n. 1, p. 05 - 21, jan-mar 2015 
Carvalho e Morais (2003, p.1), em pesquisa realizada em Portugal, afirmam que:

$\mathrm{O}$ actual estado do ensino da contabilidade necessita de reflexão séria por parte de todos os elementos a ele ligados, quer directa quer indirectamente. Se nos cingirmos ao ramo específico da Contabilidade Analítica, de Custos e/ou de Gestão, essa necessidade é por demais evidente, principalmente nos tempos que correm.

Para Santos (2003), é inegável que a educação não possa ser analisada isoladamente, sem considerarmos a sociedade-cultura envolvida, tampouco o seu momento histórico, com todos os seus efeitos sobre os indivíduos. O grande desafio contemporâneo do ensino da disciplina Contabilidade de Custos é direcionar os exemplos das aplicações teóricas para outras áreas que não abranjam somente o setor tradicional industrialmanufatureiro. Para isso, existe sólido alicerce teórico.

É necessário, então, como já mencionado, direcionar o foco do ensino para outras atividades econômicas e aplicar, nessas áreas, os sólidos conceitos construídos através do tempo, como: custo, custeio, margem de contribuição, etc.

De acordo com Solomons (1984), a maioria dos conceitos e técnicas utilizadas hoje nos modernos sistemas de custeio foi desenvolvida e se tornou de domínio público há pelo menos um século, o que demonstra que os fundamentos teóricos continuam válidos, tanto é que são empregados nos sistemas de custeio atual dentro de uma abordagem mais eficaz.

Souza e Veiga (2009) afirmam que cada vez mais a sociedade se vê diante da necessidade de ter profissionais qualificados para atenderem à demanda do mercado e, consequentemente, obterem eficiência e qualidade na produção de bens e serviços, que são essenciais para manutenção e desenvolvimento da vida. Desse modo, nota-se a importância da sintonia que o profissional deve ter com o mercado e, de forma especial, em relação a custos, na eficiência e qualidade dos produtos e serviços.

Nesse sentido, Warren, Reeve e Fess (2001) destacam que, no mundo real, algumas empresas de serviços têm também custos de material direto, e exemplificam que o combustível é um custo de material direto para uma empresa aérea, enquanto os medicamentos são custos de material direto para um paciente num hospital.

Coelho e Lins (2010) separam a informação gerada pela Contabilidade Gerencial em dois grandes grupos:

a) Informações relativas à avaliação de desempenho econômico e financeiro; e

b) Informações relativas ao desempenho de produtos e serviços.

Observa-se que as informações relativas aos indicadores relacionados aos produtos e serviços poderão contemplar informações dos setores agrícola, mineral, petrolífero, além do setor de serviços, alicerçadas e adaptadas por meio de todas as ferramentas tradicionais da Contabilidade Gerencial e de Custos e voltadas ao setor industrial.

Em pesquisa realizada por Tibola, Silveira e Mais (2012) buscou-se identificar os atributos de qualidade percebidos pelos alunos em disciplinas de Administração e de Contabilidade para o estudo de custos e concluiu-se que:

a) a demanda dos alunos por exercícios práticos e a relação das teorias com casos práticos também podem ser compreendidas como uma característica da personalidade dos estudantes contemporâneos;

b) os estudantes estão expostos continuamente a novos conteúdos e desejam ter um papel ativo no processo de ensino-aprendizagem, especialmente quando for possível 
combinar os conteúdos discutidos em sala de aula com as informações e atividades que se apresentam no seu dia a dia.

Os referidos autores ainda acrescentam que essa observação pode ser especialmente aplicável à área de custos, já que constitui uma área relevante para as organizações e que se reveste de significativa complexidade para aqueles que iniciam nessa atividade, pois inclui, além de cálculos, a correta interpretação de dados e identificação de valores que subsidiarão a formação dos preços de mercadorias e, em última instância, ajudarão a determinar o desempenho geral das organizações.

O panorama da perda do peso relativo da indústria manufatureira no conjunto da economia e o ensino contemporâneo da Contabilidade de Custos devem ser alvos de reflexão e direcionamento dos docentes responsáveis por formarem profissionais sintonizados com o mercado de trabalho. Portanto, cabe ao educador provocar e incentivar o debate sobre os rumos da educação, refletindo sobre que conhecimentos, competências e habilidades são indispensáveis aos futuros profissionais da área contábil (PADOAN; CLEMENTE, 2010).

A esse respeito, Carlin e Martins (2003) afirmam que, caso haja uma falta de atualização didática dos docentes ao novo cenário da educação, poderá ocorrer um desequilíbrio entre os métodos, as técnicas de ensino e o perfil dos alunos, prejudicando o ensino da Ciência Contábil. Pensando em perfil do professor, Feracine (1990) argumenta que os professores vivem o que realizam. Isso revela que a metodologia praticada em sala de aula deixa transparecer toda uma mentalidade, um estilo de vida, um sistema de valores, uma cosmovisão. Em suma, a filosofia de vida do educador.

Silva (2011) adverte que o ensino de Contabilidade de Custos, especialmente nos cursos de graduação, segue imune às transformações no ambiente, posto que continua a ser abordado nos referidos cursos da mesma maneira que era há décadas. Desse modo, apesar de se esperar que o ensino da matéria se apresente como agente de vanguarda, portanto, protagonista de uma realidade na qual se vive, ele vem se portando, na melhor das hipóteses, como mero espectador dos acontecimentos.

Ressalta-se o papel do professor na condução do processo ensino-aprendizagem, já que ele pode direcionar a disciplina Contabilidade de Custos aos anseios e à realidade contemporâneos. Gil (2008) ensina que o planejamento do ensino, num plano mais concreto, fica sob a responsabilidade dos professores e se alicerça nos planejamentos curriculares. Assim, os professores decidem sobre os objetivos a serem alcançados pelos alunos, o conteúdo programático a ser desenvolvido e os recursos que vão utilizar.

Carlin e Martins (2006) efetuaram pesquisa com o objetivo de identificar e analisar os procedimentos, técnicas e métodos de ensino utilizados por professores do Curso de Ciências Contábeis de quatro Escolas da Região da Grande São Paulo. Perceberam que o interesse demonstrado pelos professores participantes sugere que outras dimensões do processo ensino-aprendizagem devam ser investigadas junto aos estudantes e professores desses cursos.

Silva (2011) comenta que o ensino de Contabilidade de Custos, nos cursos de graduação, está dissociado do atual ambiente produtivo, reproduzindo conhecimentos relativos a um modo de produção já ultrapassado.

Itoz e Mineiro (2005), ao se referirem aos principais aspectos a serem ministrados na disciplina Contabilidade de Custos, indica que a ementa da disciplina geralmente contempla os seguintes pontos a serem tratados: introdução à contabilidade de custos; princípios e terminologia contábeis aplicados aos custos; tratamento de receita e despesas na contabilidade de custos; custeamento e controle de material direto; mão de 
obra direta e indireta e dos custos gerais de produção; produção por ordem e produção contínua; sistemas de acumulação de custos; coprodutos e subprodutos; relação custovolume-lucro; custo padrão e análise de variâncias.

O Conselho Federal de Contabilidade (2008) divulgou o que chamou de Proposta Nacional de Conteúdo para o Curso de Graduação em Ciências Contábeis, na qual as disciplinas são divididas em conteúdos de formação básica, profissional, teórico-prática e disciplinas optativas. A disciplina Contabilidade de Custos está classificada como de conteúdo profissional e apresenta a seguinte ementa:

a) Introdução à Contabilidade de Custos, classificação e nomenclatura de custos;

b) Sistema de custeamento e sistema básico de custos;

c) Implantação de sistemas de custos e custos conjuntos.

Na proposta do CFC é possível observar que, dentre os objetivos da disciplina, destacase a aplicação dos conceitos de custos para fins de avaliação e controle de estoques, cuja bibliografia nacional básica e de total aceitação é o livro "Contabilidade de Custos" de autoria do eminente Professor Dr. Eliseu Martins.

Raupp e colaboradores (2009) também efetuaram pesquisa com o objetivo de analisar os elementos norteadores do ensino da disciplina Contabilidade de Custos nos cursos de graduação ofertados no Estado de Santa Catarina e chegaram às seguintes conclusões:

a) Os conceitos e termos mais citados pelos pesquisados e relacionados às ementas da disciplina foram: custos, preços e relação custo, volume e lucro;

b) Dentre os conteúdos ministrados pelos docentes, destacaram-se como mais citados: custeio variável, ponto de equilíbrio e margem de contribuição;

c) Em relação à metodologia de ensino, as aulas tradicionais expositivas se destacam, vindo, em seguida, os exercícios;

d) No processo de avaliação, evidenciou-se, em primeiro lugar, a prova tradicional, seguida por trabalhos acadêmicos e exercícios;

e) A bibliografia de maior consulta é o Livro Contabilidade de Custos de autoria do professor Eliseu Martins.

O panorama econômico contemporâneo entrevê ação pedagógica diferenciada da maneira tradicional pela qual o docente responsável ministra a disciplina Contabilidade de Custos nos cursos de graduação em Ciências Contábeis. Nesse sentido, Silva, Vasconcelos e Castro (2002) afiançam que, uma dessas ferramentas que compõe o perfil deste profissional, e que se tem tornado cada vez mais estratégica para obtenção de bons resultados, é a gestão de custos, que vem se modificando com as novas características do sistema econômico.

O que se percebe é que o mundo contemporâneo empresarial é surpreendente e totalmente diferente daquele momento em que os custos de manufatura tinham relevância e o chão de fábrica era fácil de visualizar. Essa nova característica da economia brasileira, que torna o chão de fábrica cada vez mais distante da sala de aula e do mercado de trabalho torna desafiador o ensino da disciplina Contabilidade de Custos.

2.3 Panorama Econômico Contemporâneo da Perda do Peso Relativo da Indústria Manufatureira no Conjunto da Economia Brasileira - "Desindustrialização".

A perda do peso relativo da indústria manufatureira no conjunto da economia brasileira, também denominado de "desindustrialização", não é fato novo, porém o pífio desempenho do setor manufatureiro tradicional nos últimos anos tem estimulado inúmeras reflexões. Bonelli, Pessoa e Matos (2012) entendem que o medíocre

R. Cont. Ufba, Salvador-Ba, v. 9, n. 1, p. 05 - 21, jan-mar 2015 
desempenho da indústria de transformação, a partir de meados de 2011, provocou uma nova onda de análises.

Patury (2013) realça que, a participação da indústria no PIB caiu de $26 \%$ m, em 2008, para 14\%, em 2012, e poderá ir para 8\%, em 2018. Bonelli, Pessoa e Matos (2012), com visão não otimista e de longo prazo, afirmam que, mantido esse ritmo em progressão linear, a indústria desapareceria pouco antes do fim deste século, ou seja, em 2092.

Para Schymura e Pinheiro (2013), o que parecia uma preocupação restrita a correntes mais estruturalistas se tornou uma preocupação mais geral em 2010, isto é, no momento em que se percebeu que a indústria de transformação nacional havia efetivamente estagnado. $\mathrm{O}$ mundo acadêmico e empresarial não pode ficar à margem desse panorama que suscita reflexões e ações diferenciadas.

A desindustrialização é a perda de participação do setor industrial no Produto Interno Bruto - PIB nacional. Sob a ótica de Bonelli, Matos e Pessoa (2012), desindustrialização é a perda sistemática de peso da indústria na economia, processo que começou no Brasil em meados dos anos de 1970. Desse modo, a desindustrialização ocorrerá, se a participação da indústria no PIB for menor do que a esperada, em decorrência das características da economia.

De acordo com Bacha e Bolle (2012), o auge da indústria de transformação no Brasil se deu em 1985, quando ela respondeu por $25 \%$ do PIB. Desde então, a importância da indústria vem declinando, paulatinamente, até atingir 15\% em 2011; e complementam que, se a indústria perdeu no que tange à participação no PIB, os serviços ganharam.

O Gráfico 1 apresentado em seguida mostra a participação da Indústria de Transformação na formação do PIB brasileiro, no período histórico entre 1947 e 2009, com projeção para 2010. De uma participação média em torno de $11 \%$, entre 1947 e 1949, atingiu um máximo de 27,2\%, em meados da década de 1980. A partir daí, a participação reduziu para um intervalo entre 15,0\% e 16,0\% de 1997 a 2010.

Gráfico 1. Evolução da participação da indústria de transformação no PIB brasileiro

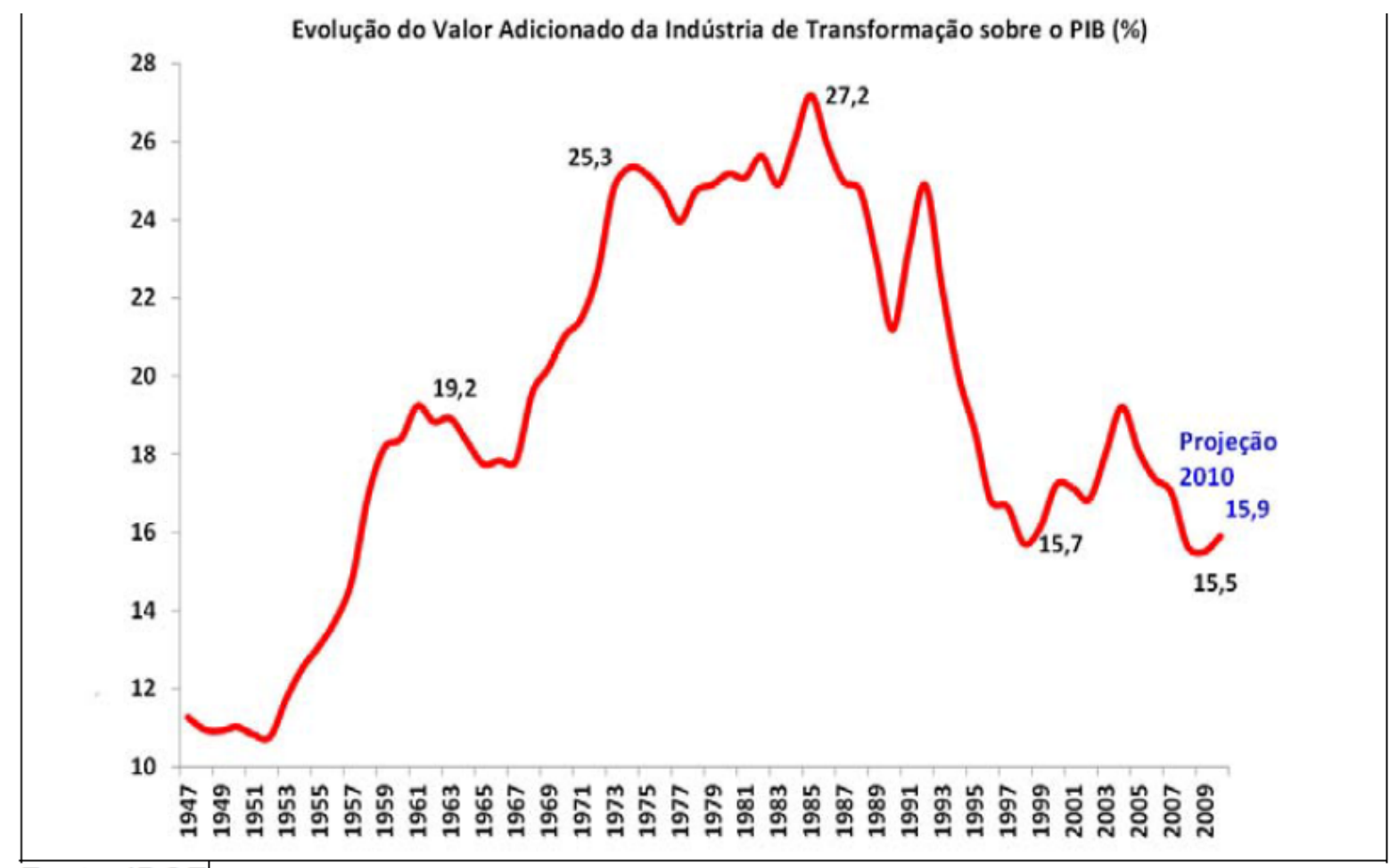

Fonte: IBGE

R. Cont. Ufba, Salvador-Ba, v. 9, n. 1, p. 05 - 21, jan-mar 2015 
O Gráfico 1 demonstra que o ápice da participação da indústria de transformação no PIB brasileiro se deu entre os anos de 1985 e 1987 (27,7\%) e, a partir daí, observa-se constante declínio e uma recuperação em 1993 para, em seguida, ocorrer significante decréscimo.

De acordo com Cano (2012), uma das principais causas dessa desindustrialização tem sido a política cambial prevalecente, instaurada depois do Plano Real. A indústria foi acometida do que a literatura econômica denomina de "doença holandesa" e associa essa "doença" à valorização do câmbio provocada pela melhoria das relações de troca, além do aumento da transferência de recursos financeiros do exterior.

O Gráfico 2 exposto em seguida, faz uma comparação entre os comportamentos dos serviços, da agropecuária e do setor industrial, destacando, ainda, a indústria de transformação. O período demonstrado vai também de 1947 a 2009. Neste último ano, a participação dos serviços no PIB foi de $68,5 \%$, a agropecuária contribuiu com $6,1 \%$ e a indústria geral com $25,4 \%$. Isoladamente, a indústria de transformação adicionou $15,5 \%$ à riqueza produzida.

Gráfico 2. Componente dos setores econômicos no PIB brasileiro

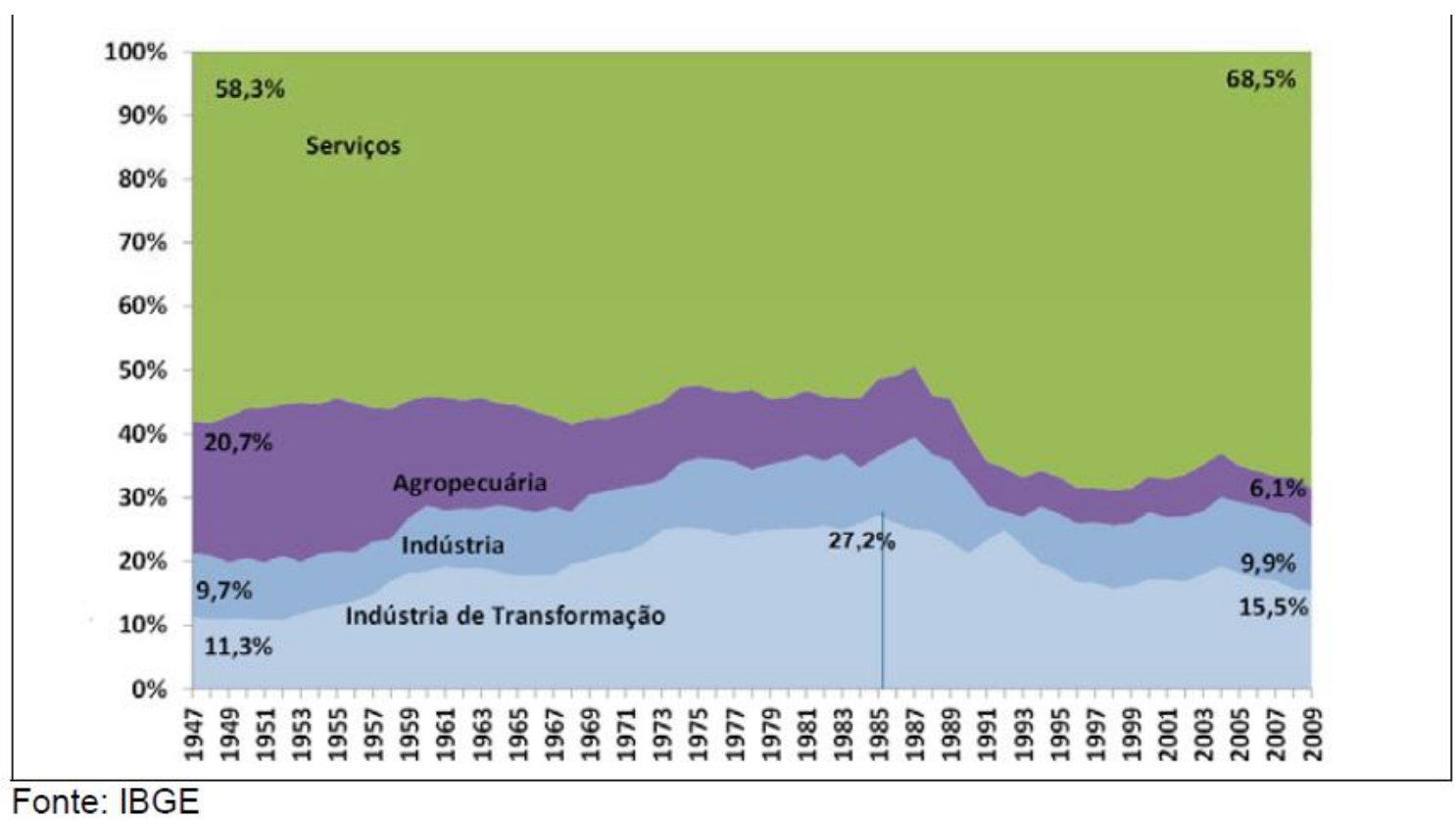

O Gráfico 2 demonstra a atual predominância do setor de serviços $(68,5 \%)$ no PIB brasileiro, quando comparado aos demais setores econômicos.

Outro aspecto a abordar é que o efeito econômico imediato da desindustrialização é a migração da mão de obra que antes ocupava o chão de fábrica para o setor de serviço. Bacha (2012) confirma essa migração, quando afirma que uma bonança interna gera naturalmente um deslocamento da mão de obra da indústria para os serviços, provocando, desse modo, uma desindustrialização, conforme medida pela participação da indústria no PIB.

Schymura e Pinheiro (2013) afirmam que, em temos de geração de empregos, se considerados os efeitos diretos e indiretos, se destacam comércio, agropecuária, calçados, madeira e mobiliário, mas, se for feita uma ponderação pela qualidade do emprego, levando em conta escolaridade, rotatividade e salário médio, a vantagem do ponto de vista do processo em cadeia se transfere para o setor de serviços. 
O setor de serviços merece, pois, atenção de todos os agentes econômicos e, de forma muito especial, do mundo acadêmico, já que neste, dentre os inúmeros objetivos, sobressai o preparo da mão de obra direcionada ao mercado de trabalho.

Para responder à questão de pesquisa e atender aos objetivos estabelecidos, o trabalho será direcionado aos aspectos metodológicos, uma vez que, para Gil (2008, p. 26), o objetivo fundamental da pesquisa é descobrir respostas para problemas mediante o emprego de procedimentos científicos.

\section{METODOLOGIA}

Esta pesquisa classifica-se como exploratória, por ter a finalidade de averiguar de que maneira a disciplina Contabilidade de Custos está sendo ministrada no curso de graduação em Ciências Contábeis, em face do panorama econômico de desindustrialização brasileira e especificamente, se os professores ministrantes da referida disciplina estão procurando adaptação e sinergia ao novo panorama econômico, com o desafio de preparar o aluno a esse contemporâneo e diferenciado mercado de trabalho.

Com base nas informações obtidas, procurou-se compreender as possíveis adaptações (técnicas, métodos e procedimentos) dos professores da disciplina Contabilidade de Custos ao ensino, tendo em vista o cenário da desindustrialização da economia nacional. $\mathrm{O}$ instrumento usado para coletar os dados trata-se de um questionário com 13 questões fechadas sobre a condução do ensino da disciplina Contabilidade de Custos no curso de graduação em Ciências Contábeis, relacionando-as ao panorama de desindustrialização da economia brasileira. Foi solicitado ao professor respondente, entre outras questões, que assinalasse o grau de concordância com a adaptação de conteúdo, método de ensino, ementa normalmente utilizada e preparação do aluno ao mercado de trabalho e consideradas as seguintes opções: 1. "concordo totalmente", 2. "concordo parcialmente", 3."não concordo nem discordo", 4."discordo parcialmente" e 5."discordo totalmente".

O instrumento para coletar os dados foi aplicado no $2^{\circ}$ semestre de 2013 aos docentes da disciplina Contabilidade de Custos, no plano da graduação e vinculados a três Instituições de Ensino Superior (IES): Instituição Privada de Ensino Superior localizada na capital do Estado de São Paulo, a qual oferece inúmeros cursos de graduação, entre os quais se destacam: Ciências Contábeis, Administração e Direito; Instituição Pública de Ensino Superior, também localizada no Estado de São Paulo, porém no município de Santo André e oferta inúmeros cursos de graduação, dos quais se destacam: Administração, Economia e Ciências Contábeis; Instituição Particular de Ensino Superior, na cidade de Belém, capital do Estado do Pará, a qual possui inúmeros cursos de graduação, dentre os quais podemos apontar: Ciências Contábeis, Administração e Direito.

A população foi composta por 8 docentes em cada IES, sendo a amostragem aleatória, não estratificada, e o número de respondentes foi de $8 \mathrm{em}$ cada IES. Inicialmente analisamos verticalmente todas as respostas e, para melhor compreensão, serão expostas as respostas obtidas. As perguntas e respostas comuns serão aglutinadas para, em seguida, chegar-se à análise dos resultados e conclusões.

\section{ANÁLISE DO RESULTADO}

R. Cont. Ufba, Salvador-Ba, v. 9, n. 1, p. 05 - 21, jan-mar 2015 
Serão expressos os questionamentos feitos aos professores de Contabilidade de Custos e as respectivas respostas serão alvos de análises.

\section{Questão 1. O professor ensina a disciplina Contabilidade de Custos?}

Esta pergunta procura verificar se o docente que responde ao instrumento ensina, entre outras disciplinas, Contabilidade de Custos, pois é comum o professor lecionar mais de uma disciplina. Nesse sentido, a ideia é centrar o instrumento no docente da referida disciplina. A totalidade dos docentes respondeu que, entre outras disciplinas, leciona a disciplina Contabilidade de Custos.

\section{Questão 2. Inclusão do tema da perda do peso relativo da indústria manufatureira} no conjunto da economia brasileira, também conhecido como "desindustrialização".

Esta pergunta busca identificar se o docente introduz o tema "desindustrialização da economia" em suas aulas. A partir de agora, separamos as respostas dos docentes da instituição de educação superior privada, localizada no norte do País, das dos docentes que trabalham nas instituições de educação privada e pública localizadas na região sudeste do Brasil, ou seja, no Estado de São Paulo.

2.1 Respondentes da Região Norte do Brasil:

\begin{tabular}{|l|r|l|}
\hline Discordam totalmente & $40 \%$ & Não incluem o tema \\
\hline Concordam parcialmente & $40 \%$ & Incluem timidamente \\
\hline Discordam parcialmente & $10 \%$ & Pouco ou quase nada incluem \\
\hline
\end{tabular}

2.2 Respondentes da Região Sudeste do Brasil - IES Particular

\begin{tabular}{|l|r|l|}
\hline Discordam totalmente & $80 \%$ & Não incluem o tema em suas aulas \\
\hline Não concordam nem discordam & $20 \%$ & São indiferentes ao tema \\
\hline
\end{tabular}

2.3 Respondentes da Região Sudeste do Brasil - IES Pública

\begin{tabular}{|l|l|l|}
\hline Discordam totalmente & $100 \%$ & Não incluem o tema em suas aulas \\
\hline
\end{tabular}

Todos os docentes que se submeteram ao questionário lecionam, entre outras disciplinas, Contabilidade de Custos. Percebe-se que o tema voltado para a perda do peso relativo da indústria manufatureira no conjunto da economia brasileira, também conhecido como "desindustrialização", é de pouca inclusão e debate pelos docentes em sala de aula, pois somente $40 \%$ dos docentes da IES da região norte do Brasil responderam afirmativamente.

Questões 3 a 6. O docente exemplifica, em suas aulas, a contabilização e a informação de custos, tendo como alvo as empresas industriais?

As perguntas de 3 a 6 têm como objetivo verificar se o docente está orientando/ensinando a produção de informação, direcionando essa informação para o usuário que atua na empresa industrial, agroindustrial, comercial ou nas prestadoras de serviços.

3.1 Respondentes da IES Privada do Norte

\begin{tabular}{|c|c|c|}
\hline Concordo totalmente & $100 \%$ & Dos docentes exemplificam \\
\hline \multicolumn{3}{|c|}{ 3.2 Respondentes da Região Sudeste do Brasil: IES Privada } \\
\hline Concordo totalmente & $90 \%$ & Docentes que exemplificam \\
\hline
\end{tabular}




\begin{tabular}{|c|c|l|}
\hline Concordo parcialmente & $10 \%$ & Docentes que exemplificam \\
\hline 3.3 Respondentes da Região Sudeste do Brasil: IES Pública \\
\hline Concordo totalmente & $50 \%$ & Docentes que exemplificam \\
\hline Concordo parcialmente & $50 \%$ & Docentes que exemplificam \\
\hline
\end{tabular}

Quanto ao foco da disciplina, voltado para a empresa industrial manufatureira, ainda prepondera entre os docentes, porém a IES pública localizada na região sudeste do Brasil acusa que $50 \%$ dos docentes exemplificam a contabilização e a produção de informação tendo como alvo a empresa prestadora de serviços.

Questão 7. Questiona se o docente usa outros métodos de ensino que não seja o tradicional (aula presencial, quadro, pincel ou giz, prova tradicional).

Esta pergunta tem como objetivo verificar se o professor inova na metodologia de ensino da disciplina Contabilidade de Custos ou se usa o método tradicional.

7.1 Respondentes da Região Norte do Brasil:

\begin{tabular}{|l|r|l|}
\hline Discordo totalmente & $60 \%$ & Os docentes ensinam o tradicional \\
\hline Concordo parcialmente & $20 \%$ & Buscam alternativas \\
\hline Não concordo nem discordo & $20 \%$ & São indiferentes \\
\hline 7.2 Respondentes da Região Sudeste do Brasil - IES Particular \\
\hline Discordo totalmente & $60 \%$ & Docentes ensinam o tradicional \\
\hline Discordo parcialmente & $40 \%$ & Não ensinam o tradicional \\
\hline 7.3 Respondentes da Região Sudeste do Brasil - IES Pública \\
\hline Discordo totalmente & $50 \%$ & Ensinam de forma tradicional \\
\hline Concordo parcialmente & $50 \%$ & Buscam alternativas \\
\hline
\end{tabular}

Quanto à metodologia tradicional de ensino (aula presencial, quadro, pincel ou giz, prova tradicional, etc.) foi a que predominou, porém se observou que esse fato tende a se modificar, em especial na IES pública localizada na região sudeste do Brasil, pois $50 \%$ dos docentes apresentam alternativas ao método tradicional de ensino da disciplina Contabilidade de Custos.

\section{Questão 8. O docente atualizou, nos últimos três anos, o conteúdo da disciplina Contabilidade de Custos?}

Esta questão tem como objetivo saber se o docente, em face do panorama de desindustrialização da economia brasileira, teve ação de adaptar, nos últimos três anos, o conteúdo da disciplina a essa realidade nacional.

\subsection{Respondentes da Região Norte do Brasil}

\begin{tabular}{|l|r|l|}
\hline Discordo totalmente & $40 \%$ & Não adaptaram o conteúdo \\
\hline Concordo parcialmente & $60 \%$ & Buscaram atualizar o conteúdo \\
\hline
\end{tabular}

8.2 Respondentes da Região Sudeste do Brasil - IES Particular

\begin{tabular}{|l|r|l|}
\hline Concordo totalmente & $80 \%$ & Adaptaram o conteúdo \\
\hline Não concordo nem discordo & $20 \%$ & Ficaram indiferentes à adaptação \\
\hline
\end{tabular}

R. Cont. Ufba, Salvador-Ba, v. 9, n. 1, p. 05 - 21, jan-mar 2015 
8.3 Respondentes da Região Sudeste do Brasil - IES Pública

\begin{tabular}{|l|r|l|}
\hline Concordo totalmente & $100 \%$ & Adaptaram o conteúdo \\
\hline
\end{tabular}

Quanto à adaptação do conteúdo da disciplina Contabilidade de Custos às transformações econômicas contemporâneas, percebeu-se relevante iniciativa dos docentes, nas IES localizadas na região sudeste do Brasil, tanto na IES privada como na pública. Na IES localizada na região norte do Brasil, a adaptação foi menor do que nas demais IES.

Questão 9 a 12. Foi perguntado se o docente entendia que os conhecimentos perpassados nas aulas poderiam ser aplicados preferencialmente nas empresas industriais, prestadoras de serviços, empresas comerciais ou empresas voltadas ao agronegócio.

Estas questões têm o objetivo de identificar o entendimento do professor, quanto à aplicação dos conhecimentos ministrados na disciplina Contabilidade de Custos às diversas atividades empresariais.

Os docentes da disciplina Contabilidade de Custos, nas três IES pesquisadas, direcionam seus conhecimentos para aplicação, de preferência, na empresa industrial manufatureira. A aplicação na atividade voltada à prestação de serviços obteve pequena aceitação pelos docentes das IES localizadas na região sudeste do Brasil (10\%) e, no que tange à atividade comercial, não se constataram manifestações favoráveis à aplicação dos conhecimentos de Contabilidade de Custos.

Questão 13. A bibliografia usada ou recomendada pelo docente, em sua maioria, é voltada para a empresa industrial?

O objetivo desta questão é verificar se o docente estimula a consulta, recomenda ou usa bibliografia que expressa ou exemplifica conhecimentos de custos que não sejam exclusivos da atividade industrial.

13.1 Respondentes da Região Norte do Brasil

\begin{tabular}{|l|r|l|}
\hline Concordo totalmente & $100 \%$ & A totalidade usa/recomenda \\
\begin{tabular}{|c|c|l|}
\hline 13.2 Respondentes da Região Sudeste do Brasil - IES Particular \\
\hline Concordo totalmente & $20 \%$ & Usa/recomenda a bibliografia \\
\hline Concordo parcialmente & $40 \%$ & Não indicam exclusivamente \\
\hline Discordo parcialmente & $40 \%$ & Indicam bibliografia de outras áreas \\
\hline 13.3 Respondentes da Região Sudeste do Brasil - IES Pública \\
\hline Concordo totalmente & $50 \%$ & Usa/recomenda a bibliografia \\
\hline Concordo parcialmente & $50 \%$ & Não indicam exclusivamente \\
\hline
\end{tabular}
\end{tabular}

Quanto ao referencial bibliográfico, foi possível observar a preponderância das indicações voltadas às empresas industriais, em especial pelos docentes que trabalham na IES do norte do Brasil, porém se observou incipiente transformação desse comportamento em relação aos docentes das IES localizadas na região sudeste, pois o percentual apurado está em torno de 50\%. Desse modo, a outra metade dos docentes está indicando livros e outras referências voltadas para outras atividades (serviços e agronegócio) que não sejam exclusivamente a industrial. 


\section{CONCLUSÃO}

A consulta aos docentes, alvos da pesquisa, que trabalham nas três IES e ministram, entre outras, a disciplina Contabilidade de Custos, permite as assertivas de que os conteúdos programáticos, métodos ou propostas de ensino, em nível de graduação, da disciplina Contabilidade de Custos estão, de forma incipiente, buscando sintonia com o momento econômico do setor industrial brasileiro, caracterizado pela perda do peso relativo da indústria manufatureira no conjunto da economia brasileira, também denominado de "desindustrialização".

A disciplina Contabilidade de Custos tem seus fundamentos relacionados à contabilização e consequente produção de informações, tendo como alvo principal a empresa industrial manufatureira tradicional; percebe-se, porém, embrionária iniciativa voltada à empresa prestadora de serviços.

O ensino tradicional da disciplina Contabilidade de Custos, o qual privilegia a aula presencial, quadro, pincel, giz e prova escrita, ainda predomina, contudo tende a mudanças, em especial, nas IES localizadas na região sudeste do Brasil.

O conteúdo da disciplina Contabilidade de Custos está passando por lenta adaptação às transformações econômicas contemporâneas, principalmente pelos docentes das IES localizadas na região sudeste do Brasil. O referencial bibliográfico, cuja indicação prepondera, é voltado para a empresa industrial, mas foi possível observar tímida iniciativa de indicação de outras voltadas às empresas prestadoras de serviços e empresas atuantes no agronegócio.

Diante do que se pôde averiguar e, embora não se possa generalizar, as evidências mostram que os alunos que cursam a disciplina Contabilidade de Custos não estão sendo preparados, em sua plenitude, para trabalhar em empresas que oferecem maior oportunidade de trabalho no panorama econômico contemporâneo.

$\mathrm{O}$ resultado da pesquisa permite perceber que, por parte dos docentes, a disciplina Contabilidade de Custos deve explorar os conteúdos adaptados à realidade do mercado de trabalho, com exercícios e indicações bibliográficas, no que concerne à contabilização e análise dos fatos relacionados aos custos das empresas prestadoras de serviços e das empresas atuantes no setor agropecuário. Entende-se que essa mudança de postura e de paradigma e entendimento dessa necessidade por parte dos docentes é a contribuição da pesquisa para ao ensino da disciplina Contabilidade de Custos e para o avanço da Ciência da Contabilidade.

Por fim, reconhece-se a limitação da pesquisa, em virtude do número restrito da população e se propõe que pesquisa futura aumente tal número, além de incluir na população os alunos e não somente os professores da disciplina Contabilidade de Custos, fato que contribuirá, sobremaneira, para melhor compreensão do assunto.

\section{REFERÊNCIAS}

ALMEIDA, M. de. Padrões de política industrial: a velha, a nova e a brasileira. Rio de Janeiro: ed. Civilização Brasileira, 2013.

BACHA, E. BOLLE, M.B de. O futuro da indústria no Brasil. Rio de Janeiro, ed. Civilização Brasileira, 2013.

Bonança externa e desindustrialização: uma análise do período 20052011. Rio de Janeiro: Editora Civilização Brasileira, 2012. 
BENNIS, W.G.; O'TOOLE, J. O novo rumo da Escola de Administração. Havard Bussiness Review. Fev. 2012.

BONELLI, R.; PESSOA, S.; MATOS, S. Desindustrialização no Brasil: fatos e interpretação. Rio de Janeiro: Editora Civilização Brasileira, 2013.

BURSAL, N. I. German cost accounting education and the changing manufacturing environment. Management Accounting Research, 1992, 3, 39-51.

CANO, W. A desindustrialização no Brasil. Economia e Sociedade, Campinas, v. 21, Número Especial, p. 831-851, dez. 2012.

CARDOSO, R.L; MÁRIO, P. do C.; AQUINO, A.C. B de. Contabilidade Gerencial: mensuração, monitoramento e incentivos. $1^{\mathrm{a}}$ ed. - $2^{\mathrm{a}}$ reimpr.- São Paulo: Atlas, 2007.

CARLIN, I.P.; MARTINS, G. de A. Métodos de Sucesso no Ensino da Contabilidade. Revista Brasileira de Contabilidade - ano XXXV - no. 157 - janeiro/fevereiro 2006 - pp. 65 a 79.

CARVALHO, J.B. da C.; MORAIS, Ó.M.M.; O Ensino da Contabilidade Analítica ou de Custos em Portugal. VIII Congreso del Instituto Internacional de Costos e I Congreso de la Asociación Uruguaya de Costos. Punta del Este, Uruguay, 2003.

COELHO, C.U.F. LINS, L. dos S. Teoria da Contabilidade. Abordagem Contextual, Histórica e Gerencial. São Paulo: Atlas, 2010.

CONSELHO FEDERAL DE CONTABILIDADE. Proposta nacional de conteúdo para o curso de graduação em Ciências Contábeis. Brasília: Ed. Fundação Brasileira de Contabilidade, 2008.

DRUCKER, P. F. O que podemos aprender com a administração japonesa. Havard Exame - As ideias que revolucionam a administração. Biblioteca de Administração de Empresas. São Paulo: Ed. Abril, 1970.

FERACINE, L. O professor como agente de mudança social. São Paulo: Ed. EPU, 1990.

GIL, A. C. Didática do ensino superior. São Paulo: Atlas, 2008.

Métodos e técnicas de pesquisa social, $6^{\text {a }}$ ed. São Paulo: Atlas, 2008.

GUPTA, S.; MARSHALL, L. L. Congruence between entry-level accountant's required competencies and accounting textbooks. Academy of Educational Leadership Journal, vol. 14, n. 1, 2010.

INSTITUTO BRASILEIRO DE GEOGRAFIA E ESTATÍSTICA - IBGE. Sistema de Contas Nacionais. Disponível em: http://www.sidra.ibge.gov.br/bda/cnt/default. Acesso em: 16. Mai. 2013. 
ITOZ, C.de; MINEIRO, M. Ensino-Aprendizagem da Contabilidade de Custos: Componentes, desafios e Inovação prática. Enfoque - Reflexão Contábil, Vol.24 - pg. 53-65 N.2 Julho-Dezembro/2005.

MALAN, P.S. Apresentação. O futuro da Indústria no Brasil. Desindustrialização em debate, editora Civilização Brasileira. Rio de Janeiro, 2013.

MARION, J.C. RIBEIRO, O.M. Introdução a Contabilidade Gerencial. São Paulo: Saraiva, 2011.

MARTINS, G. de A.; CARLINS, I.P.; Métodos e Sucessos no Ensino da Contabilidade. Revista Brasileira de Contabilidade - ano XXXV - no. 157 - janeiro/fevereiro 2006 - pp. 65 a 79.

MEDEIROS, P.P de; LIMA, D.H. S de; ARAÚJO, A.O. Dificuldades de Aprendizagem de custos e alternativas de superação. INTERFACE - Natal/RN - v.2 - n.1 - jan/jun 2005.

SILVA, R.N.S. da. O impacto do novo ambiente fabril no ensino tradicional de custos. Uma abordagem sobre o ensino da disciplina Contabilidade de Custos. Boletim da Universidade Federal do Rio de Janeiro. Faculdade de Administração, Economia e Contabilidade, Fev. 2011.

SOLOMONS, D. The historical development of costing. In: SOLOMONS, D. Collected paper on accounting and accounting education. Vol. 2.History, education, and management accounting.New York, N.Y., Garland Publishing, 1984.

PADOAN, F.A. da C. CLEMENTE, A. A interdisciplinaridade no ensino da Contabilidade - um estudo empírico da percepção dos docentes. In: VI CONGRESSO BRASILEIRO DE CUSTOS. Anais... São Paulo, 1999.

PATURY, F. Primeiro Plano. Revista Época, Edição 779, p.29 de 29 de Abril de 2013.

RAUPP, F.M; AMBONI, N. CUNHA, D.R. DUARTE, J.L. AGOSTINETO, R.C. O ensino de contabilidade de custos nos cursos de graduação em administração do Estado de Santa Catarina. ABCustos Associação Brasileira de Custos - Vol. IV $\mathrm{n}^{\circ} 2$ mai/ago 2009.

RIOS, S.P.; ARAÚJO JR, J.T. Desempenho industrial e vantagens comparativas reveladas. Rio de Janeiro, Editora Civilização Brasileira, 2013.

SANTOS, R.V. dos. Jogos de Empresas aplicados ao processo de ensino e aprendizagem de Contabilidade. Revista Contabilidade \& Finanças - USP, São Paulo, n. 31, p. 78 - 95, janeiro/abril 2003.

SCHYMURA, L.; PINHEIRO, M.C. Política Industrial Brasileira: Motivação e diretrizes. Rio de Janeiro. Editora Civilização Brasileira, 2013. 
SOUZA, A.A de. VEIGA, W.E. Contribuição das Disciplinas de Contabilidade na Formação do Graduando em Administração de Empresas. Caderno de Pesquisa em Administração, São Paulo, V.1, n³, 2º. Sem. 2009.

TIBOLA, J.A. SILVEIRA, A. MAIS, I. Atributos de Qualidade em Disciplinas de Administração e Ciências Contábeis voltadas para o Estudo de Custos: o Ponto de Vista dos Discentes. Revista de Educação e Pesquisa em Contabilidade. REPeC, Brasília, v. 6, n. 4, art. 3, p. 383-398, out./dez. 2012.Disponível online em www.repec.org.br.

WARREN, C.S; REEVE, J.M.; FESS, P.E. Contabilidade Gerencial. São Paulo: Pioneira Thomson Learning, 2001. 